\title{
Speaking Assessment at Secondary and Higher Secondary Levels and Students' Deficiency in Speaking Skill: A Study to Find Interdependence ZAKIA NOOR MATIN
}

\begin{abstract}
For a comprehensive development of students' communication skills, reading, writing, listening and speaking are equally important to be emphasized. At the learning process, assessment is the final step where the learners get feedback of what they have been taught and how much they have learned. The study aims to show the current approach of assessing students' English speaking skill (the most important medium of communication) at the Secondary and Higher Secondary levels, and how far this approach helps students develop language skills. Finally, the study intends to find out the reason of students' reluctance in improving English speaking skill and evaluate their sufferings at the tertiary level. A survey was conducted among one hundred students of three private universities. Majority of them have come from Bangla medium institutions. The syllabuses (2008), text books and question papers (2006 to 2010) are used as reference for this study. The research was exploratory and three private universities of Dhaka city were selected as study area. Irrespective of the discipline of the study, 100 students were interviewed through a structured questionnaire. The academic practice of the students in secondary and higher secondary levels was portrayed retrospectively and the obstacles they were facing at the tertiary level were analysed according to the objective of the study. This is also a finding which shows a rift between the objective of introducing Communicative Language Teaching (CLT) and the assessment technique followed by National Curriculum and Text Books Board.
\end{abstract}

\section{Introduction}

In our education system at present time, much emphasis is given to improve students' English communication skills. Though speaking and listening are the two common means of communication, education planners 
of Primary, Secondary and Higher Secondary levels give less emphasis on these skills. The institutions and the syllabuses do not provide students much scope to improve these skills. The texts provided by the board contain chapters and exercises for practicing those skills; however, the teachers and the students remain reluctant to work on them. The teachers do not want to waste their time working on them. Students do not want to study the chapters. In that case, both students and teachers tend to give priority to complete the syllabus; instead of improving skills. Furthermore, students do not have the opportunity to communicate in English because Bangla speaking parents, family and friends surround them. As a result, after completing secondary and higher secondary education, students have to suffer when they reach the tertiary level. The study identifies the reasons behind students' reluctance and the subsequent difficulties they face.

\section{Objective of the study}

This study is intended to find out the reasons of students' (at the S.S.C and the H.S.C levels) reluctance in improving their English speaking skill and how the secondary and higher secondary curriculums contribute to such reluctance. The study is also intended to evaluate how such reluctance makes them suffer at the tertiary level.

\subsection{Specific Objectives}

- To find out the reasons of students' reluctance in improving English speaking skill in the S.S.C and the H.S.C levels

- To reveal the gap between the curriculum and purpose of language study

- To show how this gap makes the students suffer at the tertiary level. 


\section{Literature Review}

\subsection{Purpose of Introducing CLT at the S.S.C and the H.S.C Levels}

The main purpose of learning English is to communicate in English effectively and English has become the main language for global communication. As a developing country, Bangladesh has to follow the global standard of communication. As a result, Communicative Language Teaching (CLT) was introduced in Bangladesh in the 1990s (Teaching Quality Improvement in Secondary Education Project, Module-1). The main purpose is to develop students' skills in English language.

Communicative Language Teaching means that the emphasis is on language in use rather than language as structure. It concentrates largely on the spoken form of English. Even though spoken is an important part, reading, writing and listening skills are also focused on. Practice of pronunciation, stress and intonation is a vital component; language is based on real life situations. Hence, the students' communicative competence is the objective, rather than linguistic competence. (Teaching Quality Improvement in Secondary Education Project, Module-1)

\subsection{Four Skills of Language}

For language development, four skills are equally important to be developed. As Peregoy and Boyle state, "Listening, speaking, reading and writing also occur naturally together in learning events in school at all great levels, even though traditionally they were taught separately" (107).

As Harmer suggests "One skill cannot be performed without another. It is impossible to speak in a conversation if you do not listen as well, and people seldom write without reading" (52). As the main purpose of teaching a foreign language is to help students achieve communicative competence, each of the skills should be similarly practiced. 


\subsection{Importance of Speaking}

Someone's fluency in speaking indicates his or her competence in that language. A person may write without proper knowledge of grammar and sentence structure; he or she can read without proper pronunciation, listen without proper listening skill; whereas, speaking skill depends on the total knowledge of a language (vocabulary, grammar, sentence structure, listening etc). When we take part in an interaction, we not only speak but also listen. If we use wrong English, we fail to communicate properly and get an instant feedback of this failure. It is an important part of everyday interaction. The first impression of a person's language skill depends on his/her ability to speak fluently and comprehensively.

Brown \& Yule mention that language has two functions: transferring information (transactional function) and maintaining social relationships (interactional function). Interactional spoken language depends not on accuracy and clarity, rather it is characterized by shift of topic and short turns. Transactional spoken language is characterized by longer turns and clear topic. Effective transference of data is the goal of transactional spoken language and therefore, interlocutors are engaged for negotiation of meaning (1-3). Brown \& Yule summarize the above stating that where as interactional language is "listener oriented", transactional language is "message oriented" (11-16). Oral English also plays an important role in developing reading and writing skills. As Rivers says, "When we read and write, we call upon what we know of the language orally" (20).

\subsection{Necessity of Spoken Fluency}

From the perspective of our country, fluency in speaking is needed for professional purpose, like doing business and diplomatic jobs, and for higher studies. At the private sector, various local and multinational companies have created a large job field for our young generation. Here, the most required qualities of candidates are presentation skills and fluency in speaking which can be noted from the job advertisements in newspapers. Sometimes at an interview the academic result is ignored if someone's 
presentation skill in English is satisfactory. Candidate's speaking skill makes him or her confident at the interview board because they can easily make the answers. For further professional development, this skill also helps people. What we generally see, people with fluency and smart presentation skills sometimes do better than those who are not skilled enough. On the other hand, students who are going abroad for pursuing higher studies must have spoken fluency. At today's workplaces our communication abilities are becoming more important with the advancement of technology. At the workplaces where everything is conducted through voice mail, teleconference, video conference, power point presentation, seminar, meeting, conference and above all through teamwork, peoples' ability to speak fluently has become essentially important. Stevens and others have predicted that the ability to communicate effectively - both orally and in writing - will become even more valuable as technology intensifies the influence of messages in the workplace (5).

\subsection{Necessity of Speaking Assessment}

Proper testing is necessary in skills development because without testing, the process of achieving competence remains incomplete. Testing makes students sincere enough to learn things properly. In countries where English is the second language, students do not get that much opportunity to use their English skills. And even if they get any chance to use, they do not get proper feedback of whether they are using correct English or not. Institutions are the best places to implement what they have learned and where they can be assessed and corrected. In our context, it is a common psychology that students learn language to achieve good score in examinations, not to develop skills. Speaking assessment is equally important like the other skills. Most teachers would accept that "if you want to encourage oral ability, then test oral ability" (Hughes 44). If students know they have to present something or give an oral test in English at the exam and their success in language use will depend on their performance, they will be serious enough to develop their speaking skills. 
Although through writing and reading tests, speaking and listening ability can be judged indirectly, these tests provide no comprehensive assessment of learners' communicative ability.

\subsection{Current Approach of Speaking Assessment at the S.S.C and the H.S.C Levels}

The English text books, provided by the board for the S.S.C and the H.S.C levels, contain some activities on speaking, like storytelling, dialogue making (English for Today for 9-10 and 11-12), but very few teachers and students practice these activities in classrooms. They remain busy practicing reading comprehension and writing composition as the question papers of the board exams do not contain any part for speaking and listening (Sample question papers from 2006 to 2010). The students do not have to present anything during their classes and face VIVA. As almost all important examinations do not include oral test, both teachers and students neglect practicing oral English. It seems to them their main purpose of language skill development is reading not speaking.

In fact, speaking is the most difficult skill to assess. It was mentioned, "there are not yet good answers to questions about the criteria for testing these skills and the weighing of these factors" (Kitao \& Kitao, Testing Speaking). Another difficulty is, it is hard to assess a number of students within a short time because the examiner is put under pressure (Heaton 55). Kitao \& Kitao also mentioned that scoring is the most difficult as the assessment includes grammar, pronunciation, fluency, content, organization, and vocabulary (Testing Communicative). These are probably the reasons for which our education planners remain less interested to assess students' speaking ability.

\subsection{A Reversed Scenario at the Tertiary Level}

At the tertiary level, especially at universities, students receive a completely different environment where they are encouraged to communicate in English and most of the lectures are delivered in English. 
Teachers sometimes have to face problems with students who are not good at listening and speaking. Though at almost all the universities, communicative English courses are introduced, it is hard to overcome the deficiency within a short time. Students of other disciplines remain less serious about English courses.

\section{Methodology}

This is a descriptive exploratory research which followed survey method for data collection. Both primary and secondary data have been used to support this study. To collect primary data a structured questionnaire (see appendix) was designed to administer the study. Secondary data was collected from publications, research studies, journals and websites. Three private universities of the capital were selected purposively for the study. Students of those universities were the respondents and they were selected randomly irrespective of their sex, residence, medium of their previous study and present discipline of education. Sample size of the study was limited to 100 due to financial and time constraint.

For the quality control of the survey, the questionnaire was pre tested from the class room where the researcher carried out her lectures and the findings of the pre-test were incorporated duly.Formal consent was duly collected before each interview was conducted. The questionnaire was designed with both close and open ended questions. Data were coded before entry into the software and SPSS 17 was used for data analysis. For analysis of data, Microsoft Excel has been used. To entry data, coding option has been used at the initial stage. Basic statistical techniques of different measures of central tendency have been used in analysing the data.

\section{Findings}

The survey was conducted among 100 students of three private universities of Dhaka city, namely Daffodil University (29\%), Stamford University Bangladesh (41\%) and University of Liberal Arts (30\%) 
(Figure1). Among the respondents $45 \%$ was male the rest was female; 7 out of 10 came from urban background. Context reflects that parental education had an inner impact on students' skills development and it was also revealed that fathers of $50 \%$ students were postgraduates whereas $73 \%$ mothers were only graduates or less qualified.

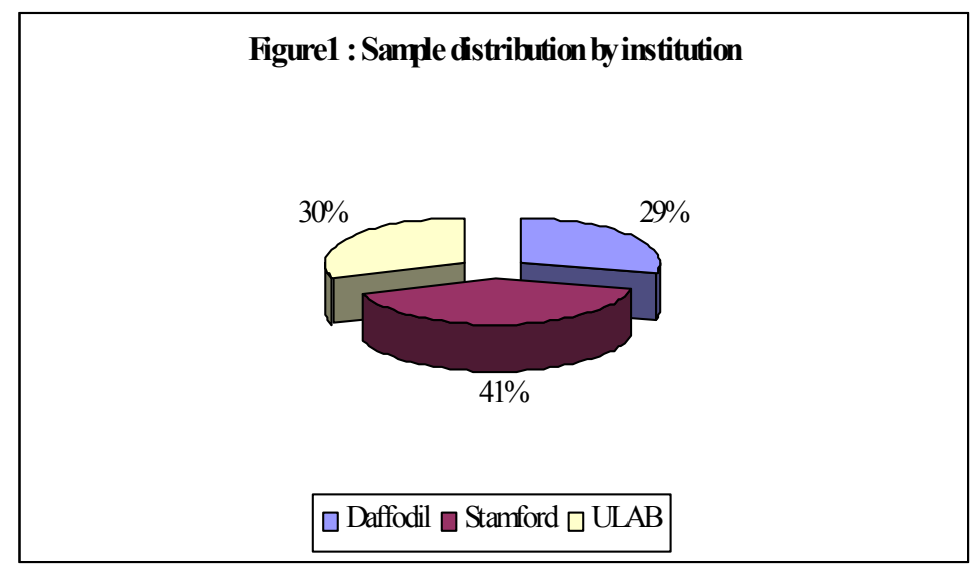

Majority (98\%) of the respondents completed the S.S.C and the HSC causes from Bangla medium institutions. The respondents were retrospectively inquired about the class room communication and the medium of lecture delivery at the secondary and higher secondary level; only $6 \%$ of them reported that their class room communication was in English and 32\% had the classroom environment of both languages. Majority (62\%) received lectures in Bangla.

Though the curriculum and texts provided by the National Curriculum and Text Book Board (NCTB) of the country give emphasis on 4 skills (reading, writing, speaking and listening) of language, 33\% of students respond that they did not realize the existence of this emphasis. Moreover, $47 \%$ of them acknowledged that they were not forced to speak in English by their teachers and $85 \%$ of them said that their class room environment failed to provide them any opportunity to use their skills of English speaking and listening. 7 students out of 10 gave their opinion about the 
English syllabus of the S.S.C and the H.S.C courses which according to them is not good enough for improving listening and speaking skills. At the secondary and higher secondary levels only $15 \%$ respondents had to appear in oral test in English, only 7\% had to give presentation in English and only $3 \%$ of English medium institutions said that their question papers carry marks in English speaking (Figure 2).

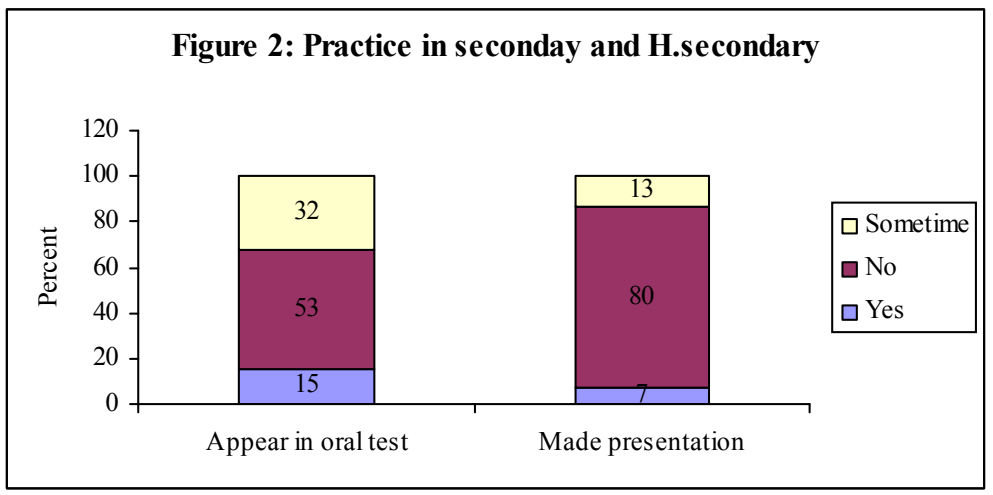

The result articulated so far closely identified that the students did not think that schools played an important role in improving their speaking skill and they rarely sat for an oral assessment. Classroom environment did not also provide any opportunity to implement their skills.

\begin{tabular}{|lcc|}
\hline \multicolumn{3}{l}{ Table-1: Reason for not understanding lecture } \\
when delivered in English \\
\hline & $\mathrm{N}$ & $\%$ \\
\hline Pronunciation problem & 18 & 32.1 \\
Teacher's fast delivery & 30 & 53.6 \\
Don't know English & 2 & 3.6 \\
Unable to understand & 5 & 8.9 \\
Grammatical problem & 1 & 1.8 \\
\hline Total & 56 & 100.0 \\
\hline
\end{tabular}

Though it is not unusual, once the respondents enter at the tertiary level, they need to face reverse experience. $98 \%$ of the respondents said that at the 
tertiary level, the lecture was delivered in English; 81\% said they needed to present orally and $86 \%$ needed to face VIVA.

Half of the respondents failed to understand lectures properly when it was delivered in English and they identified several reasons for their failure (Table-1). On the other hand, $61 \%$ faced difficulties in performing well at VIVA at the tertiary level and nervousness was identified as the major cause (Table-2).

\begin{tabular}{|lcc|}
\hline \multicolumn{3}{l}{ Table-2: Type of difficulties faced in VIVA } \\
\hline Problem in speaking English & $\mathrm{N}$ & $\%$ \\
Nervousness & 14 & 20.3 \\
Hesitation & 42 & 60.9 \\
Don't understand word meaning & 8 & 11.6 \\
Don't understand lecture & 3 & 4.3 \\
Total & 2 & 2.9 \\
\hline
\end{tabular}

But only $18 \%$ respondents acknowledged the role of their previous school environment which helped them develop their speaking skills. Rest of the respondents identified private tutor, internet, watching movie, reading newspaper and coaching center as their source of skill development (Figure 3).

Figure 3 :From where English fluency was developed

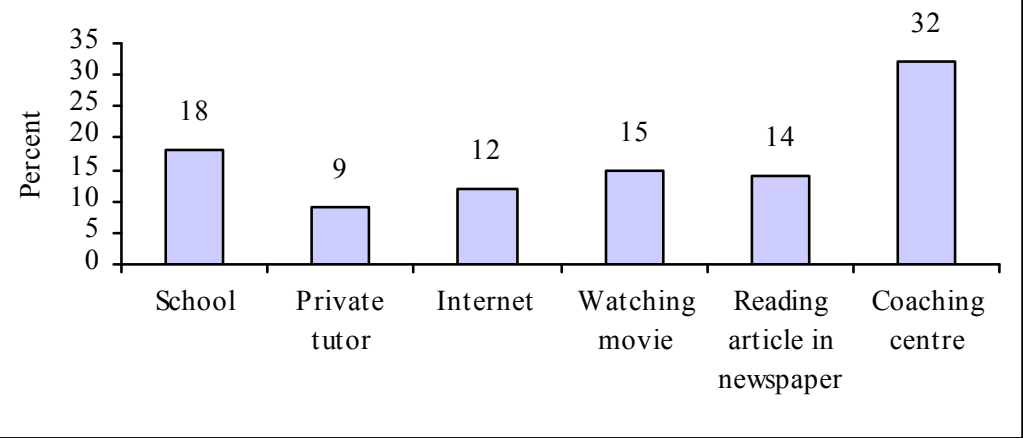




\section{Discussion}

From the above findings, it has been identified that students having middle class family education status go to Bangla medium institutions for higher studies. Their family education plays an important role in their speaking development. Students do not get an environment at home which can encourage them in speaking English. When they are sent to institutions, their reluctance becomes intensified.

Three reasons for students' reluctance have been observed:

a) As the classroom environment does not encourage students develop speaking skills and the teachers' delivery of speech is in Bangla, students do not get any motivation from the classroom environment.

b) As there is no assessment for speaking ability and students do not get any mark for it, they have no more enthusiasm in developing speaking skills.

c) As they have some other sources to develop their speaking ability, their dependence on and expectations from schools and colleges become reduced.

In another finding, it has been found that the texts provided by the NCTB for the S.S.C and the H.S.C courses give emphasis on the four skills. But the question papers tell a different thing. Most of the students agreed with the fact that their texts contained activities of speaking and listening skills, but the question papers did not contain any part on these. So a gap exists between the objective of the course and its implementation.

Finally, it has been recognized when the students enter the tertiary level after completing the S.S.C and the H.S.C courses, they have to face a lot of difficulties, like not understanding the lectures delivered in English, feeling nervous while presenting speeches at VIVA. The reason is that they did not 
face this situation before. They never had to present anything and face any oral test when they were at schools and colleges.

\section{Recommendations}

Our National Board of Education may revise the design and the curriculums of English syllabuses of the S.S.C and the H.S.C. The planners can change the way of assessing students' language skill at board exams. At the exams, beside reading and writing, marks can be allotted for speaking and listening test. Teachers may take this test at a separate time just as the practical exams of Physics, Chemistry, and Computer Science are conducted. At these examinations, students have to give oral presentation before teachers and externals. After that, on the basis of listening to something, a question answer session can be held where they have to participate in a conversation and their listening ability will be judged at the same time.

More teachers' training programs can be conducted by our National Board of Education where language teachers will be encouraged and instructed to deliver their lectures in English and to provide students space where they can implement their language skills. After the lecture, a question answer session in English can be conducted during class hour. Teachers' main purpose should not be only completing texts; rather they have to be sincere enough to help students improve their language skills.

Students have to appear in English exams (1 ${ }^{\text {st }}$ paper and $2^{\text {nd }}$ paper) which carry 200 marks at their term exams in every class. These 200 marks can be divided according to skills, not according to seen and unseen comprehension. It is not necessary to distribute the mark equally. At least if 20 marks can be allotted for speaking assessment, the objective of CLT would be successful. During the class hour teachers can take the speaking and the listening assessment by involving students into various activities and they can add this mark with the final exam. 
Almost all the universities conduct communicative language courses. These courses should emphasize more on speaking and listening skills. Throughout the secondary and higher secondary levels, students enrich their grammar, vocabulary, reading and writing skills. So if they get much scope for oral presentation, public speaking and conversation at tertiary level, they might be able to implement their previous knowledge on other skills which they already have practiced at the secondary and higher secondary levels.

\section{Limitations of the Study}

Though the objective of the study was well defined and it was administered according to a defined methodology, some limitations need to be discussed for future improvement.

- Only private universities were selected here for data collection; random inclusion of other public universities as well as technical institutions or medical colleges might draw dynamic findings.

- The universities for data collection were purposively selected due to time and money constraint.

- The expansion of sample size might depict more statistically unbiased result; financial and time constraint also had an impact in the current study.

- Study area was only in the capital, universities situated in other small cities could be included for further comparison.

\section{Conclusion}

In this fast communicative world, without having a proper communicative competence, it becomes very difficult to achieve success at any field. Our National Board of Education should perceive the truth. For this reason, with the aim of developing students' English communication skills, CLT approach has been introduced in our education system. In spite 
of achieving success at some areas, our students are still lagging behind. They failed to achieve comprehensive success at English communication skills, especially in speaking skills. A complete success of anything depends on proper planning, implementation and monitoring. There exists a gap between our education planning and its implementation; moreover, the education planners are still following the traditional method of language assessment. The students' purpose of language learning is still to achieve a good score and not to achieve language proficiency. There are so many private coaching centers where within a short duration, English spoken courses are conducted and the students tend to go to these centers to improve their spoken fluency. But it is to be remembered that schools and colleges are the largest fields of education. If these fields can be properly utilized, students do not have to go anywhere to achieve spoken fluency. 


\section{Works Cited}

Brown, Gillian, and George Yule. Discourse Analysis. $2^{\text {nd }}$ ed. Cambridge: Cambridge University Press, 1983. Print.

English for Today (For class 11-12). National Curriculum and Text Book Board. Dhaka. English Language Teaching Improvement Project. Dhaka: New Imran Printing Press. 2010. Print.

English for Today (For class 9-10). National Curriculum and Text Book Board. Dhaka. English Language Teaching Improvement Project. Dhaka: New Imran Printing Press. 2009. Print.

Harmer, Jeremy. The Practice of Language Teaching. $3^{\text {rd }}$ ed. UK: Longman Publishers, 1991. Print.

Heaton, James Ben. Writing English Language Tests. UK: Longman Publishers, 1989. Print.

Hughes, Arthur. Testing for Language Teachers. Cambridge: Cambridge University Press, 1989. Print.

Kitao, Kenji. S., \& Katheleen Kitao. Testing Communicative Competence (Report No. TM025214). (ERIC Document Reproduction Service No. ED398260), 1996. Web. 7 July 2012.

- - - Testing Speaking (Report No.TM025215). (ERIC Document Reproduction Service No. ED398261), 1996. Web. 7 July 2012.

Peregoy, Suzanne, \& Owen Boyle. Reading, Writing \& Learning in ESL. $4^{\text {th }}$ ed. New York: Longman, 2001. Print.

Rivers, Wilga Marie. Teaching Foreign Language Skills. Chicago: University of Chicago Press. 1968. Print.

Stevens, Betsy. "What communication skills do employers want? Silicon valley recruiters respond." Journal of Employment Counseling 42.1 (2005): 2-9. Print. 


\section{Appendix}

\section{Questionnaire}

\section{Informed Consent}

My name is Zakia Noor Matin. I am teaching at Stamford University, Bangladesh. I am conducting a survey on student's deficiency in English speaking skill. You know students coming from Bangla medium schools and colleges face a great problem in oral communication in English. To find out the reasons of this problem, I would like to conduct a survey among the university students. Now I would like to ask you a few questions. I assure you that, all information will be used for research purpose only and will be kept confidential. You have every right to keep away or to quit at anytime if you want. In the circumstances, do you give your consent to use your information?
Has not agreed
$\square$ Has agreed

Name of the Respondent:

1. Trimester:

2. Institution:

3. Residence:

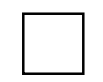

$$
1=\text { Urban }
$$

$2=$ Rural

4. Father's education

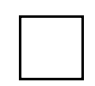

$$
1=\text { below SSC } \quad 2=\text { HSC } \text { to graduate } \quad 3=\text { Post graduate }
$$

5. Mother's education

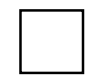

$$
\text { 1= below SSC }
$$

$$
2=\text { HSC to graduate }
$$

$3=$ Post graduate

6. Which medium did you study in at S.S.C and H.S.C levels?

$$
\text { 1= English 2= Bangla }
$$

7. What was the medium of classroom communication?
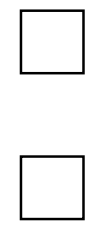

$$
\text { 1= English 2= Bangla 3=Both }
$$


8. In which language was the lecture delivered?

$$
\text { 1= English 2= Bangla 3=Both }
$$

9. Did your English text book give emphasis on 4 skills (reading, writing, listening, speaking)? $\square \quad 1=$ Yes $2=\mathrm{No}$

10. Did your teachers force you to speak in English?

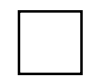

$$
1=\text { Yes } \quad 2=\mathrm{No}
$$

11. Did your classroom environment provide any place where you could implement your skills in English speaking and listening?

$$
1=\text { Yes } \quad 3=\text { No } \quad 3 o m e t i m e s
$$

12. Do you think you are fluent in English speaking?

$$
1=\text { Yes } \quad 2=\mathrm{No}
$$

13. Do you think the English syllabuses at S.S.C and H.S.C levels were good enough to improve your speaking and listening?

$$
1=\text { Yes } \quad 2=\mathrm{No}
$$

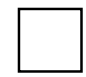

14. Did you have to appear any oral test in English?

$$
1=\text { Yes } \quad 2=\text { No } \quad 3=\text { Sometimes }
$$

15. Did you have to make any presentation at your school and college?

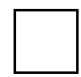

$$
1=\text { Yes } \quad 2=\text { No } \quad 3=\text { Sometimes }
$$

16. From where did you develop your fluency in English speaking?
(a) School
(b) Private tutor
(c) Internet
(d) Watching movie
(e) Reading articles in newspaper
(f) Coaching centre 
(g) Others (specify)

17. At the university level in which language is the lecture delivered?

$$
\text { 1=English } \quad 2=\text { Bangla }
$$

18. Do you understand the lectures properly if they are delivered in English?

$$
\square 1=\text { Yes } 2=\mathrm{No}
$$

19. If not, why?
(a) Pronunciation problem
(b) Teacher's fast delivery
(c) I don't know English
(d) I'm unable to understand
(e) Grammatical problem
(f) Others (specify)

20. Do you feel easy when the classroom communication is made in English?

$\square$ 1=Yes $2=\mathrm{No}$

21. If not, why? ..........................

22. Do you need to present anything orally?

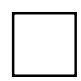

$$
1=\text { Yes } \quad 2=\mathrm{No}
$$

23. Do you need to face any VIVA?

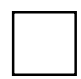

$$
1=\text { Yes } \quad 2=\mathrm{No}
$$

24. Do you face any difficulty while performing these?

$$
1=\text { Yes } \quad 2=\mathrm{No}
$$

25. If yes, why? 